\title{
Effect of antimicrobial activity of Eupatorium odoratum against clinical microbes
}

\author{
Ramesh $\mathbf{P}^{*}$ and Subramani $\mathbf{A}^{2}$ \\ ${ }^{\mathbf{1}}$ Dept of Botany Research and Development centre, Bharathiyar University, Coimbatore, India \\ ${ }^{2}$ A.A. Govt. Arts. College, Villupuram, India \\ Available online at: www.isroset.org \\ Received: 21/Jul/2018, Accepted: 18/Aug/2018, Online: 31/Oct/2018
}

\begin{abstract}
Traditional medicine is an important source of potentially useful compounds for the development of phytotherapetic agent. Antimicrobials of plant origin have enormous therapeutic potential in the treatment of infectious diseases while simultaneously migitigiting many of the side effects that are often associated with synthetic antimicrobials. In the present investigation suggested that the effect of antimicrobial activity of Epotorium odoratum against clinical microbes were performed. In the experiments of the test plant with different concentration of $25,50,75$, and $100 \mu 1$ of aqueous and methanolic leaf extract were treated against the bacteria like Bacillus sp., E.coli, Entrococcus sp., K.pnemoniae and Staph. aureus and fungi such as Aspergillus flavus, A.niger. A.terreus, Penicillium sp. and Trichoderma sp. Performed respectively. However the antimicrobial properties of E.odoratum leaf with methanolic extract of higher concentration was excellent performance when compared to other solvent of aqueous extract of same plant. It can be concluded that the plant can be used to discover natural products that may serve as lead for the development of new biomedical applications.
\end{abstract}

Keyword: Epotorium odoratum, bacteria, nutrient agar

\section{INTRODUCTION}

According to World Health Organization (WHO) more than $80 \%$ of the world's population relies on traditional medicine for their primary healthcare needs. Uses of herbal medicines in Asia represent a long history of human interactions with the environment. Plants used in traditional medicine contain a wide range of ingredients that can be used to treat chronic as well as infectious diseases. A vast knowledge of how to use the plants against different illnesses may be expected to have accumulated in areas where the use of plants is still a great importance [1]. The medicinal value of plants lies in some chemical substances that produce a definite physiological action on the human body.

The plant kingdom has been the best source of remedies for curing a variety of disease and pain. This is why medicinal plants have played a key role in the worldwide maintenance of health. Natural products of higher plants are an important source of therapeutic agents therefore, many research groups are currently screening the different biological activities of plants. [2,3].

Medicinal plants are an important therapeutic aid for various ailments. Different scientific experiments such as biological activity and antimicrobial properties on the plant components were first documented in the late 19 ${ }^{\text {th }}$ century [4].

The aqueous extract of the leaves of Eupatorium odoratum has been found to show numerous pharmacological activities such as anti-inflammatory [5] analgesic, antibacterial [6]. In this research work the leaves of Eupatorium odoratum was extracted using different solvents like petroleum ether, chloroform and ethanol. All this extracts are then subjected to analgesic activity. It has been found that the ethanolic extract also shows significant analgesic activity.

\section{MATERIALS AND METHODS}

\section{Agar well - diffusion method}

Agar well - diffusion method was followed for determination of antimicrobial activity. Nutrient agar (NA) and Potato Dextrose Agar (PDA) plates were swabbed (sterile cotton swabs) with 24 hours culture and 48 hours old broth culture of respective bacteria and fungi. Agar wells $(5 \mathrm{~mm}$ diameter) were made in each of these plates using sterile cork borer. About 25 , 50,75 and $100 \mu \mathrm{l}$ of different solvent leaves extracts of Eupatorium odoratum added using sterilized dropping pipettes into the 
wells and plates were left for 1 hour to allow a period of preincubation diffusion in order to minimize the effects of variation in time between the applications of different solutions the plates were incubated in an upright position at $37 \pm 2{ }^{\circ} \mathrm{C}$ for $24 \mathrm{hrs}$ for bacterial pathogens and $28 \pm 2^{\circ} \mathrm{C}$ for fungi. The organic solvents (aqueous and methanol) were acted as a negative control. Results were recorded, as the presence or absence of inhibition zone. The inhibitory zone around the well indicated absence of tested organism and it was reported as positive and absence of zone is negative. The diameters of the zones were measured using diameter measurement scale. Triplicates were maintained and the average values were recorded for antimicrobial activity.

\section{RESULT AND DISCUSSION}

Antimicrobial activity of herbal preparation is not an absolute characteristic and should be seen in comparative terms specifically its toxicity to the target pathogen and in target host. In recent past several contrasting reports on effectiveness of herbal antimicrobials are quite confusing; one group claims that microbes may not easily develop resistance to antimicrobial activity of herbal drugs while other group claims herbal drug resistance as a common phenomenon [7]. Those tested the herbal preparations at lower concentration found them ineffective while those tested the preparations to find out its antimicrobial activity irrespective of concentration, outcome was different Similar discrepancy is seen with observations on extracts of $E$. odorartum and related species tested on reference strains of bacteria susceptible to commonly used antimicrobials $[8,9]$. The extended testing of antimicrobial activity of green leaf extracts (EOE) and methanolic extract of green leaves (EOME) of $E$. odoratum beyond reference and laboratory strains. The different species of microbes isolated from varied sources were tested at a fixed concentration of $2 \mathrm{mg}$ of extract/ disc. And the revealed that $31.9 \%$ and $5.36 \%$ strains were sensitive to EOME and EOE, respectively.

The invitro antifungal activity assay of leaf extract of Eupatorium odoratum revealed that the ethanol extract had greater activity against the fungal isolates than the aqueous extracts.It is probable that the bioactive compounds in the leaves were more extractable in ethanol than water. This is in line with what was reported [10]. Ethanol extract of Eupatorium odoratum appeared to be more efficacious against Alternaria alternata. The inhibition zone diameters obtained was higher than the inhibition zone diameter obtained with the control (ketoconazole).

Mullika Traidej Chomnawang et al. [11] investigated the antimicrobial activity of Eupatorium odoratum against Propionibacterium acnes and Staphylococcus epidermidis have been recognized as pus forming bacteria triggering an inflammation in acne. The antimicrobial method showed that Eupatorium odoratum had strong inhibitory effects against Propionibacterium acnes. The MIC values were the $(0.039 \mathrm{mg} / \mathrm{ml})$ for both bacterial species and the MBC values were 0.039 and $0.156 \mathrm{mg} / \mathrm{ml}$ against Propionibacterium acnes and Staphylococcus epidermidis respectively

The obtained in this showed that the ethanolic extract of Eupatorium odoratum leaf inhibited the growth of all test isolates in varying degrees, indicative of the presence of the active principles in the leaf that have antimicrobial action. It had earlier been reported by several investigations that flowering plants contain antimicrobial substances [12, 13, 14].

The revealed invitro antimicrobial activity against all tested bacteria. Most susceptible organisms were Staphylococcus aureus and Pseudomonas aeruginosa which is of interest in the treatment of infections caused by these organisms. It is note that the strain of Staphylococcus aureus tested in showed resistance to two known drugs (Gentamycin and Floxapen). The strong inhibition on growth of Pseudomonas aeruginosa by leaf extract in this study is also noteworthy, as the organism is well known to be resistant to many commercial antibacterial agents [15]. This high susceptibility of Pseudomonas aeruginosa was also tested by its resistance to the control experiments using commercial antibiotics. The variation in the degree of antibacterial activities of the leaf extract presumed to be due to different levels of active compounds present in the extract. Some workers have also attributed to their observed antimicrobial effects of plants extracts to the presence of these secondary plant metabolites $[16,17]$.

The antimicrobial activity of some medicinal plants from methanolic extracts of C. monspeliensis leaves have shown an interesting activity against $P$. aeruginosa, $S$. aureus, E. faecalis with inhibition zones diameters of $18.0,20.0$ and $15.0 \mathrm{~mm}$, respectively.26 Whereas, water-methanol extracts of fruit peels of pomegranate ( $P$. granatum) have demonstrated a moderate activity when they were tested on $S$. aureus, $P$. aeruginosa and $K$. pneumoniae (13.0, 18.0 and $16.0 \mathrm{~mm}$, respectively). This activity of pomegranate peels could be attributed to tannins, for which antimicrobial activity was observed [18].

The effect of extracts of all plants for antibacterial and antifungal activities against selected plant pathogens invitro was undertaken. It was clear that, most of the plants possessed antimicrobial activity with few exceptions. However, there was a slight variation in the activity of the plant extracts. It was clear from this screening that Emblica officinalis, Curcuma longa, Cyperus rotundus and Melia azedirach extracts exhibited maximum antimicrobial activity against selected test bacterium and fungi [19].

The antimicrobial activity of crude extract (aqueous and methanolic) from Eupatorium odoratum was observed to be in dose depended manner that is $25,50,75$, and $100 \mu 1$ of extract performed. The concentration of 75 and $100 \mu 1$ leaf extract was maximum antimicrobial activity of E.odoratum against bacteria and fungi determined. The effect of antibacterial activity of 
E.odoratum leaf with aqueous extract was maximum zone of inhibition was 26.6 $\pm 9.03,16.0 \pm 5.33,11.3 \pm 3.66,26.3 \pm 8.66$ and $19.6 \pm 6.33 \mathrm{~mm}$ at $100 \mu \mathrm{l}$ concentration of plant extract against bacteria like Bacillus sp., E.coli, Entrococcus sp., K.pnemoniae, and Staph aureus observed respectively whereas mathanolic leaf extract of $100 \mu 1$ concentration was $23.6 \pm 7.6,18.3 \pm 6.0$, 22.0 $\pm 7.3,10.6 \pm 3.3$ and $19.0 \pm 6.3 \mathrm{~mm}$ with the same bacteria respectively (Table: $1,2 \&$ Fig: 1, 2).

According to the effect of antifungal activity of E.odoratum leaf with aqueous extract of $100 \mu$ concentration to be maximum zone of inhibition of 14.03 $\pm 4.60,10.06 \pm 3.30,08.33 \pm 2.60,09.33 \pm 3.10$, and 21.00 $\pm 7.00 \mathrm{~mm}$ recorded against the fungi like Aspergillus flavus, A.terreus, Penicillium sp. and Trichoderma sp. were observed respectively (Table:3,4, Fig:3,4).

In the case of methanolic solvent of $E$. odoretum leaf extract of $100 \mu$ l concentration was significant fungicidal activity like $13.6 \pm 4.50,12.3 \pm 4.10,05.5 \pm 1.80,09.3 \pm 3.10$, and $14.6 \pm 4.80 \mathrm{~mm}$ zone of inhibition recorded respectively. However, the E.odoratum plant leaf material showed higher microbial properties were represented from this it can be concluded that all these compounds are pharmacological importance as they possess the properties of antimicrobial activity were exhibited.

Table 1: Studies on the effect of antibacterial activity of Eupatorium odoratum with aqueous extract against bacteria

\begin{tabular}{|l|c|c|c|c|}
\hline \multirow{2}{*}{ Name of the bacteria } & \multicolumn{4}{|c|}{ Zone of inhibition (mm) } \\
\cline { 2 - 5 } & $\mathbf{2 5 \mu \mathbf { l }}$ & $\mathbf{5 0} \boldsymbol{\mu l}$ & $\mathbf{7 5} \boldsymbol{\mu l}$ & $\mathbf{1 0 0} \boldsymbol{\mu l}$ \\
\hline Bacillus sp. & $21.6 \pm 7.00$ & $28.6 \pm 9.30$ & $24.0 \pm 8.04$ & $16.0 \pm 5.33$ \\
\hline E.coli & $13.6 \pm 4.33$ & $13.6 \pm 4.33$ & $15.6 \pm 5.00$ & $11.3 \pm 3.66$ \\
\hline Enterococcus sp. & $14.6 \pm 4.66$ & $15.6 \pm 5.04$ & $15.0 \pm 5.30$ & $26.3 \pm 8.66$ \\
\hline K.pnemoniae & $18.0 \pm 6.04$ & $10.6 \pm 3.33$ & $22.0 \pm 7.33$ & $19.6 \pm 6.33$ \\
\hline Staph. aureus & $16.6 \pm 5.33$ & $15.0 \pm 5.06$ & $11.0 \pm 3.66$ & \\
\hline
\end{tabular}

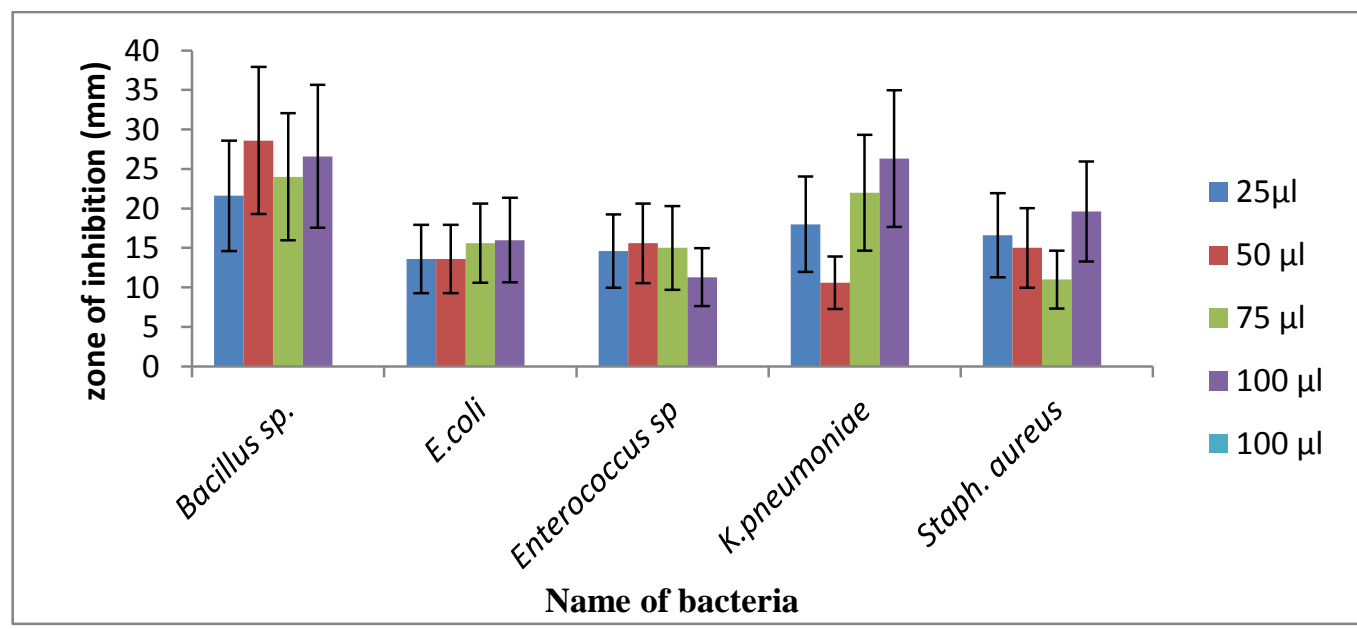

Fig 1: Studies on the effect of antibacterial activity of Eupatorium odoratum with aqueous extract against bacteria

Table 2: Studies on the effect of antibacterial activity of Eupatorium odoratum with methanol extract against bacteria

\begin{tabular}{|l|c|c|c|c|}
\hline \multirow{2}{*}{ Name of the bacteria } & \multicolumn{4}{|c|}{ Zone of inhibition (mm) } \\
\cline { 2 - 5 } & $\mathbf{2 5 \mu \mathbf { l }}$ & $\mathbf{5 0} \boldsymbol{\mu l}$ & $\mathbf{7 5} \boldsymbol{\mu l}$ & $\mathbf{1 0 0} \boldsymbol{\mu l}$ \\
\hline Bacillus sp. & $26.6 \pm 8.6$ & $16.0 \pm 5.03$ & $28.6 \pm 9.3$ & $23.6 \pm 7.6$ \\
\hline E.coli & $21.6 \pm 7.0$ & $15.3 \pm 5.00$ & $20.6 \pm 6.6$ & $22.0 \pm 7.3$ \\
\hline Enterococcus sp. & $16.6 \pm 5.3$ & $16.6 \pm 5.03$ & $16.0 \pm 5.3$ & $10.6 \pm 3.3$ \\
\hline K.pnemoniae & $22.3 \pm 7.3$ & $17.0 \pm 5.06$ & $18.0 \pm 6.0$ & $19.0 \pm 6.3$ \\
\hline Staph. aureus & $13.0 \pm 4.3$ & $21.0 \pm 7.01$ & $21.0 \pm 7.0$ & \\
\hline
\end{tabular}

\footnotetext{
Mean standard error
} 


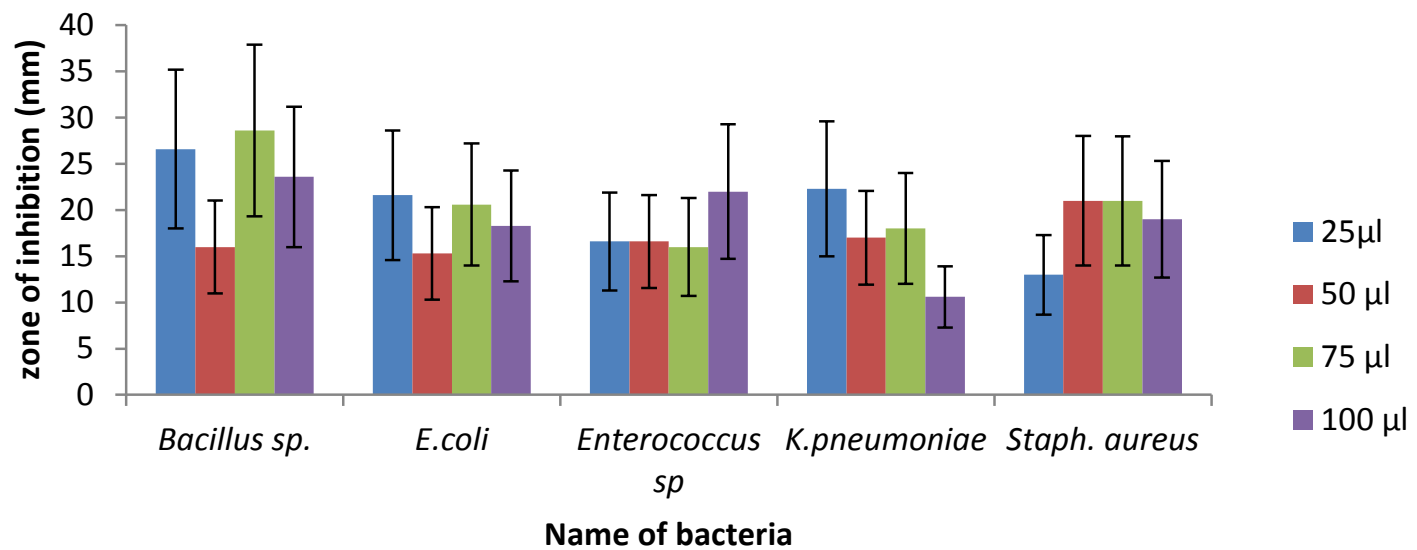

Fig 2: Studies on the effect of antibacterial activity of Eupatorium odoratum with methanol extract against bacteria

Table 3: Studies on the effect of antifungal activity of Eupatorium odoratum with aqueous extract against fungi

\begin{tabular}{|l|c|c|c|c|}
\hline \multirow{2}{*}{ Name of the fungi } & \multicolumn{4}{|c|}{ Zone of inhibition (mm) } \\
\cline { 2 - 5 } & $\mathbf{2 5 \mu \mathbf { l }}$ & $\mathbf{5 0} \boldsymbol{\mu l}$ & $\mathbf{7 5} \boldsymbol{\mu l}$ & $\mathbf{1 0 0} \boldsymbol{\mu l}$ \\
\hline Aspergillus flavus & $1.3 \pm 2.00$ & $08.30 \pm 2.06$ & $11.00 \pm 3.06$ & $14.03 \pm 4.6$ \\
\hline A.niger & $6.6 \pm 2.01$ & $08.00 \pm 2.66$ & $05.66 \pm 1.06$ & $10.06 \pm 3.3$ \\
\hline A.terreus & $5.0 \pm 1.06$ & $06.66 \pm 3.00$ & $06.00 \pm 2.00$ & $08.33 \pm 2.6$ \\
\hline Penicillium sp. & $4.6 \pm 1.33$ & $07.00 \pm 2.03$ & $07.66 \pm 2.05$ & $09.33 \pm 3.1$ \\
\hline Trichoderma sp. & $7.0 \pm 2.03$ & $15.00 \pm 5.00$ & $16.06 \pm 5.53$ & $21.00 \pm 7.0$ \\
\hline
\end{tabular}

Mean standard error

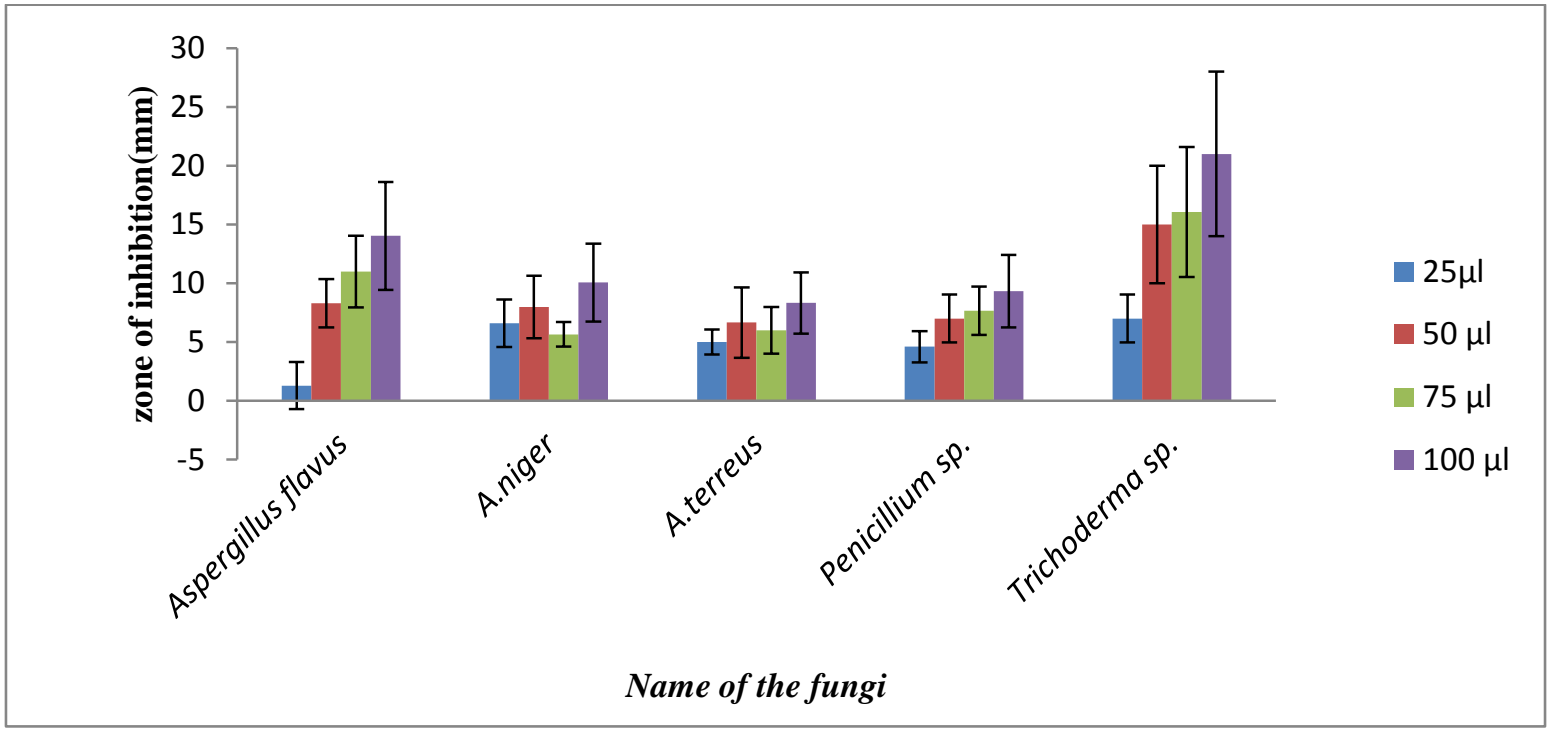

Fig 3: Studies on the effect of antifungal activity of Eupatorium odoratum with aqueous extract against fungi 
Table 4: Studies on the effect of antifungal activity of Eupatorium odoratum with methanol extract against fungi

\begin{tabular}{|l|c|c|c|c|}
\hline \multirow{2}{*}{ Name of the fungi } & \multicolumn{4}{|c|}{ Zone of inhibition $\mathbf{( m m )}$} \\
\cline { 2 - 5 } & $\mathbf{2 5} \boldsymbol{\mu l}$ & $\mathbf{5 0} \boldsymbol{\mu l}$ & $\mathbf{7 5} \boldsymbol{\mu l}$ & $\mathbf{1 0 0} \boldsymbol{\mu l}$ \\
\hline Aspergillus flavus & $5.05 \pm 1.08$ & $06.00 \pm 2.00$ & $8.03 \pm 2.76$ & $13.6 \pm 4.5$ \\
\hline A.niger & $4.06 \pm 1.05$ & $06.66 \pm 2.02$ & $9.00 \pm 3.00$ & $12.3 \pm 4.1$ \\
\hline A.terreus & $7.00 \pm 2.33$ & $05.06 \pm 1.86$ & $8.33 \pm 2.07$ & $05.5 \pm 1.8$ \\
\hline Penicillium sp. & $4.00 \pm 1.33$ & $04.64 \pm 1.66$ & $5.00 \pm 1.06$ & $09.3 \pm 3.1$ \\
\hline Trichoderma sp. & $8.33 \pm 2.07$ & $10.06 \pm 3.53$ & $5.05 \pm 1.83$ & $14.6 \pm 4.8$ \\
\hline
\end{tabular}

Mean standard error

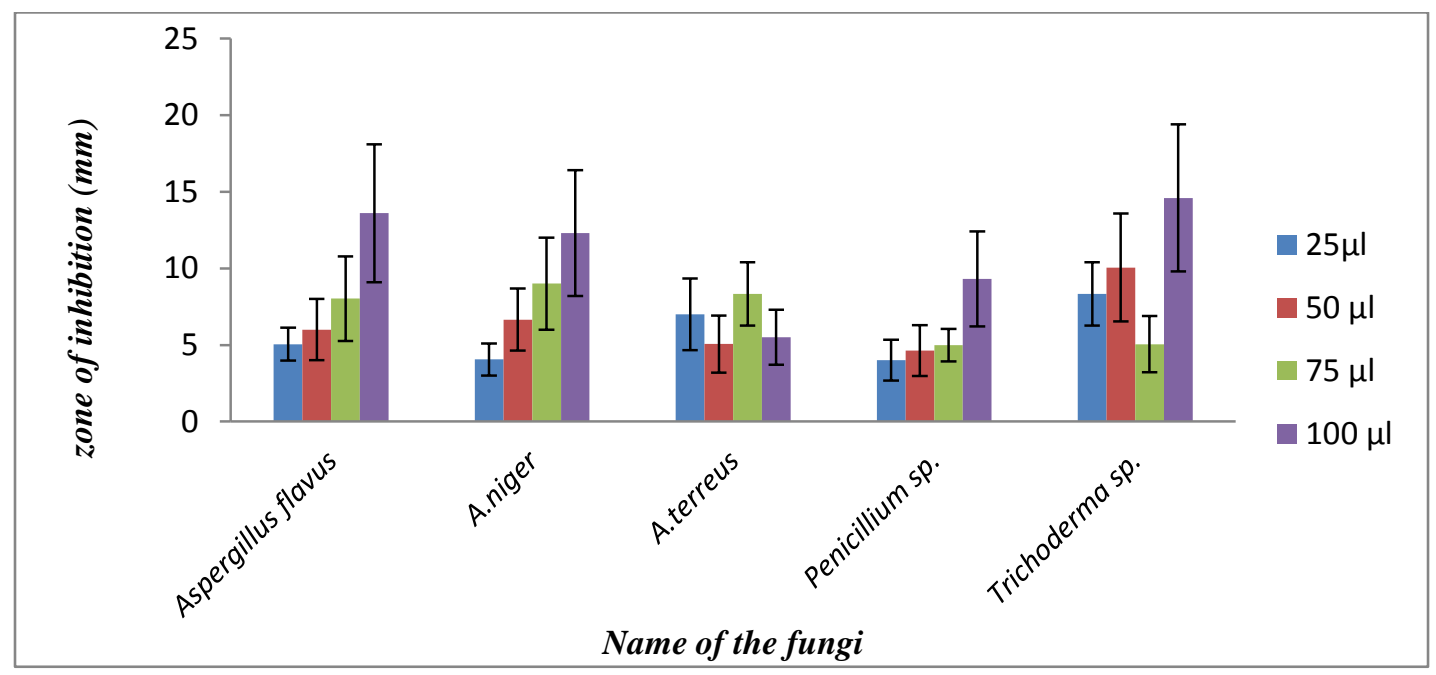

Fig 4: Studies on the effect of antifungal activity of Eupatorium odoratum with methanol extract against fungi

\section{REFERENCES}

[1] S. Willium, “Biological Sciences”, IEEE Transaction, Vol.31, Issue.4, pp.123-141, 2012.

[2] D. Diallo, B. Hveem, M.A. Mahmoud, G. Betge, B.S. Paulsen, A. Maiga, "An ethnobotanical survey of herbal drugs of Gourma district". Pharmaceutical Biology; vol. 37 pp. 80-91, 1999.

[3] R.A.A. Mothana, S.A.A. Abdo, S. Hasson, F.M.N. Althawab, S.A.Z. Alaghbari, U. Lindequist, "Antimicrobial, antioxidant and cytotoxic activities and phytochemical screening of some Yemeni medicinal plants". Evidence-Based Complementary and Alternative Medicine, vol. 7, Issue 3, pp.323-330, 2010

[4] S.J. Leu, Y.P. Lin, R.D. Lin, "Phenolic constituents of Malus doumeri var. formosana in the field of skin care". Biological and Pharmaceutical Bulletin, vol. 29 Issue 4, pp. 740-745. 2006

[5] M.Yadav, K.K. Khan, "Antimicrobial activity of some ethnomedicinal plants used by tribes of rewa, madhya Pradesh". Indian J L Sci.; vol 1, Issue 4, pp. 35-38, 2012.

[6] Michael Joyeux, Francois Mortier, Jacques Fleurentin, "Screening of antiradical, antilipoperoxidant and hepatoprotective effects of nine plant extracts used in Caribbean folk medicine". J of Phytotherapy Research, vol 9 Issues 5, pp. 228-230. 2006

[7] S. Umukoro, R. B. Ashorobi, "Evaluation of Anti-inflammatory and membrane stabilizing effects of Eupatorium odoratum". Int $J$ of Pharmacol, vol. 2 Issue 5: pp. 509-512. 2006

[8] P. Vadhana, B.R. Singh, M. Bhardwaj, S.V. Singh. "Emergence of herbal antimicrobial drug resistance in clinical bacterial isolates". Pharm Anal Acta, vol. 6 Issue 3, ..p 434-439, 2015

[9] H.R. El-Seedi, T. Ohara, N. Sata, S. Nishiyama, “Antimicrobial diterpenoids from Eupatorium glutinosum (Asteraceae)”. J Ethnopharmacol, vol. 81 Issue 2, pp. 293.

[10] S. Patel, N. Venugopalan, S. Pradeep, "Screening for antimicrobial activity of weeds". The Internet J Microbiol. Vol 4 Issue 1, pp. $26-98$. 2006

[11] J.S.Britto, "Comparative antibacterial activity study of Solanum Incanum L". J Swamy Botanical Club, vol. 18 Issue 5, pp. 81-82. 2001

[12] Mullika Traidej Chomnawang, "Antimicrobial effects of Thai medicinal plants against acneinducing bacteria". Journal of Ethnopharmacology, vol. 101 Issue (1-3),pp. 330-333 2005.

[13] S.I.Nya-Agha, , B.O Agentive, A. Sofowara, T.V. Benjamin, "Phytochemical and antibacterial studies on the essential oil of Eupatorium odoratum”. Int.J. Crude Drug Res. Vol. 25 Issue 7, pp. 49-52. 1987.

[14] C.O. Akujobi, B.N., Anyanwu, G.O. Onyeze, V.I. Ibekwe, "Antibacterial activities and preliminary phytochemical screening of four medicinal plants”. Journal Applied Sciences, vol. 7 Issue 3, pp. 4328- 4338. 2004 
[15] C.A. Obafemi, T.O. Sulaimon, D.A. Akinpelu, T.A Olugbade, "Antmicrobial activity of extracts and a germacranolide type sesquiterpene lactone from Tithania diversifolia leaf extract". Afr. J. Biotechnol vol. 5 Issue 12, pp. 1254- 1258. 2006

[16] R.T. Irvin, J.R.O. Govan, J.A.M. Fyfe, J.W. Costerton, "Heterogeneity of antibiotic resistance in mucoid isolates of Pseudomonas aeruginosa obtained from cystic fibrosis patients: role of outer membrane proteins". Antimicrobial Agents and Chemotheregoy vol. 19 Issue 6, pp. 10561063. 1981.

[17] E.I. Nweze, J.I. Okafor, O. Njoku, “Antimicrobial activities of methanolic extracts Trema guineensis (Schuman and Thorn) and Morinda lucida Benth used in Nigerian Herbal medicinal practice". J. Biol. Res. Biotechol. Vol. 2 Issue 1, 39-46. 2004

[18] C.C. Ogueke, J.N. Ogbulie, H.O. Njoku, "Antimicrobial properties and preliminary phytochemical analysis of ethanolic extracts of Alstonia bonnei. Nig”. J. Microbiol. vol 20 Issue 2, pp. 896-899, 2006

[19] Mohamed Senouci Bereksi, Hafida Hassaïne, Chahrazed Bekhechi, and Djamel Eddine Abdelouahid, "Evaluation of antibacterial activity of some medicinal plants extracts commonly used in Algerian Traditional Medicine against some Pathogenic bacteria" Pharmacogn J. vol. 10 Issue 3, pp. 507-512. 2018

[20] Saheb and Shinde, "The Antibacterial and Antifungal Activity of Medicinal Plants from Kinwat Forest" Bioscience Discovery, vol. 9 Issue 1: 79-85. 2018. 